during the first half of the last century, and finally, an abundance of Osage orange hedges obviates the nece sity for any expenditure whatever in cultivation.

The silkworm is, of course, the larva of a moth. There are several species, but one variety has been under general cultivation for centuries. The silkworm

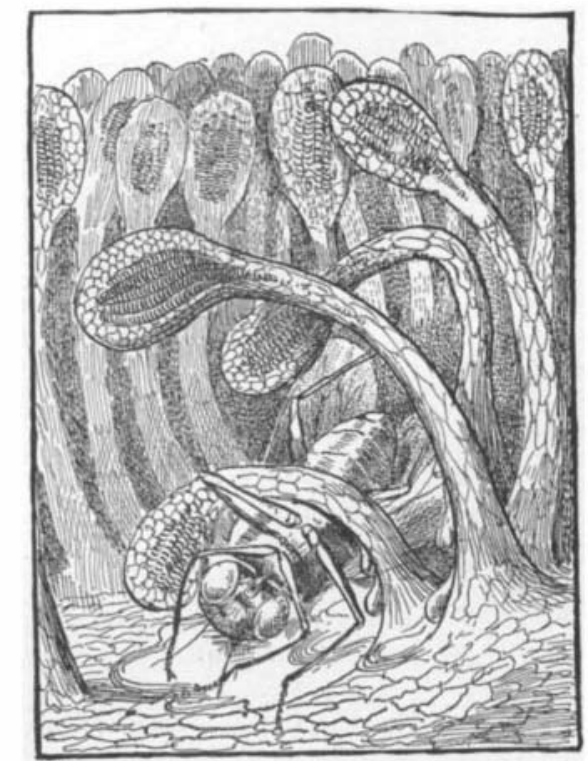

AN INSECT CAUGHT IN THE TENTACLES OF DROSERA ROTONDIFOLIS.

eggs are nearly spherical and about the size of turnip seeds. Each female produces an average of from 300 to 400 eggs, in the neighborhood of 20,000 eggs being required to make an ounce in weight. For a time after the infant worm has gnawed its way out it consumes its own weight of leaves every day. Upon attaining full growth the insect becomes restless, stops feeding and throws out silken threads. The silk is formed in a fluid condition and issues from the body of the worm in a glutinous state-apparently in a single thread. From this silk the worm constructs its cocoon, an interval of from three to five days being required to complete its imprisonment in the fragile envelope.

In order that the silken strands may not be subjected to the danger of breakage by the moth emerging from the cocoon, the cocoons are steamed until the inclosed insects are presumably dead. After this the silk may be wound off. The outer silk known as "floss" is used for carding, while the inner cocoon is tough, strong and compact and composed of a single continuous thread. It is essential that the room in which the silkworms are reared be warm in winter and well ventilated. If only a few insects are reared all the operations are usually performed on trays set on tables, but where the industry is carried on extensively there are employed deep shelves ranged one above another. The eggs when about to hatch are spread thinly and over them is placed ordinary mosquito netting on top of which is scattered finely cut leaves. The new-born worms pass through the meshes of the net in search of food and may then be transferred to any place desired. Later little arches of twigs must be provided, into the branches of which the worms mount and spin their cocoons.

\section{REFLEX ACTION OF PLANTS AS COMPARED WITH THE INSTINCTS OF INSECTS.}

$$
\text { BY J. CARTER BEARD. }
$$

We have all of us been so accustomed to wonderful stories of the wisdom of ants and of bees, as well as

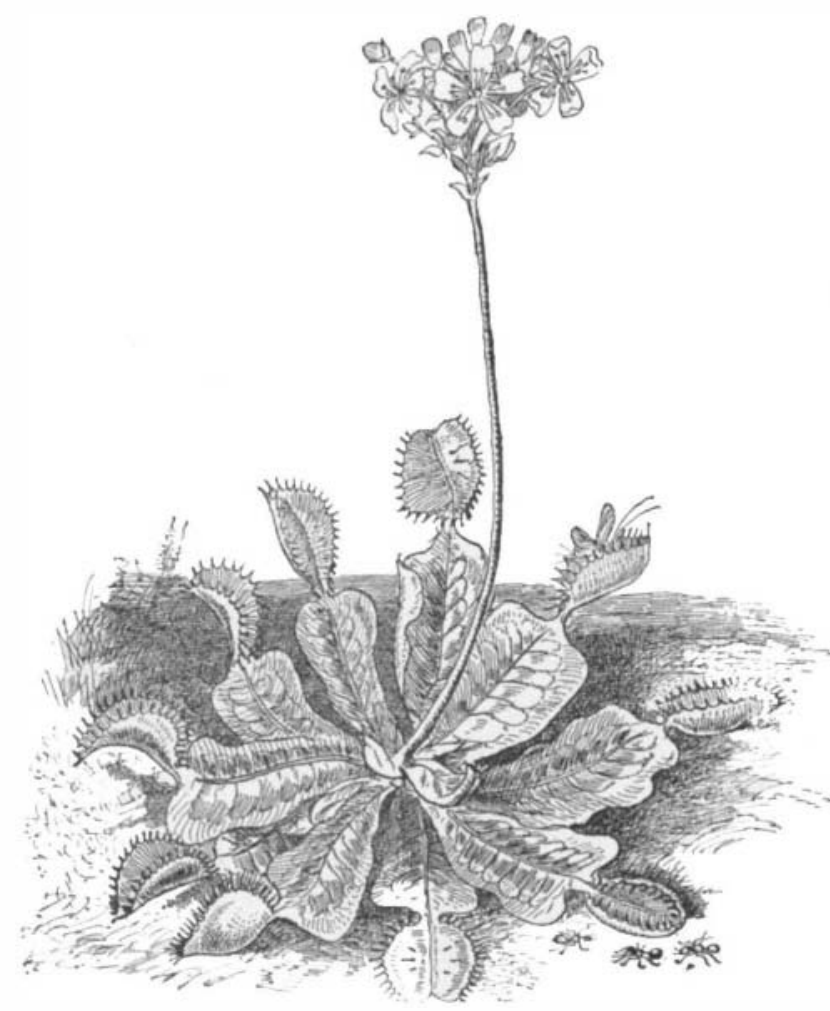

DIONEA HOSCIPULA other worthy members of entomological races, that the doubts which certain scientific investigators are beginning to entertain with regard to the truth of any assertion that attributes conscious intelligence to these little creatures, comes upon our sentimental appreciation of their ways with something like a shock.

When we consider the wonderful adaptation of means to an end, the prevision and the ingenious methods employed by many sorts of insects in carry. ing out the purposes and objects of their lives, we are indeed inclined to credit them with intelligence of a high order. It is only after we are forced to recognize the extreme limitations of this so-called intelligence, its inflexible nature, and its inability to adapt itself to other conditions than those under which it is habitually, or ordinarily exercised, that we recognize how much is wanting in the behavior of insects to furnish conclusive evidence of their possession of any intellectual capacity whatever.

Light, for example, attracts insects in general, as it does also plants, but it does not necessarily follow that vision, in the human sense of the word, belongs either to plants or to insects.

The attraction of light governs the growth, the in clination of stems and the position of leaves; th plant reaches, so to express it, out toward the ligh with all the power it has-yet it does not see: The insect has eyes or organs of vision (quite different from ours), but all we absolutely know about insects is that they are influenced by light, and to aver, without more definite knowledge on the subject, that they do anything so highly psychical as seeing (as human beings see) is not only unscientific, but not at all consistent with well ascertained facts. How unintelligent is the impulse the insect shares with the plant in seeking the light, is shown by the inane manner in which moths or beetles will flutter about a white ceiling, or plunge into a flame.

Intelligence does, indeed, direct the actions of th bee in building her comb and filling it with honey, and

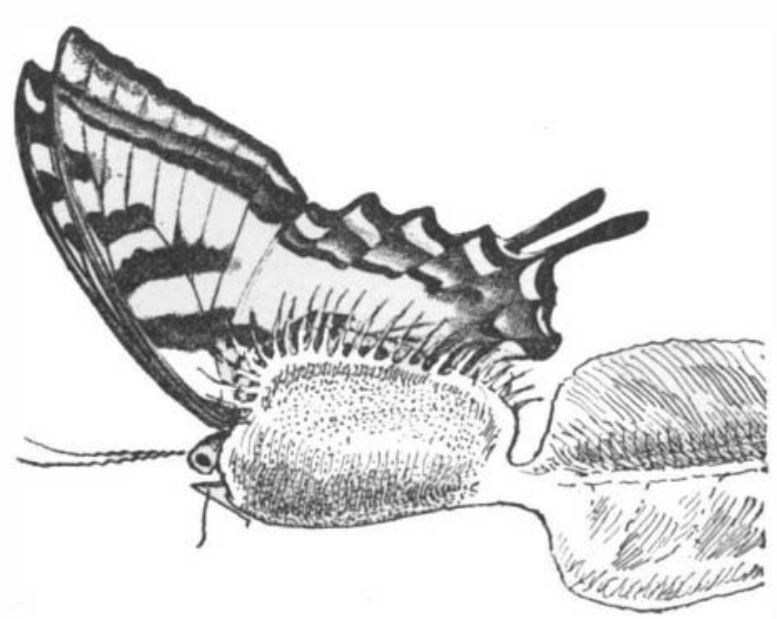

A BUTTERFLY CAUGHT IN THE TRAP.

the ant in her wonderful domestic economy; but it is an intelligence quite as much above the plane of consciousness of the bee and of the ant, as it is above that of the orchid, for instance, in the admirably in genious manner in which the flower enlists the aid of the insect in conveying pollen. Reflex actions of this kind mimic intelligence on the part of the actor something perhaps as do the movements of the boat said to have been invented by Tesla, which, worke by etheric waves, proceeds in any given direction. curns or dives beneath the surface of the water upon which it floats, not in obedience to any dirrnting powe on board, but at the will of a person operating a bat tery on the shore.

The stimuli of whatever nature, light, heat, som form of electric action, magnetism, or even more subtle, occult forces which move insects, seem to have the unvarying and unthinking nature of those supplied to mere machinery; the result is much the same as in an automaton, blind perseverance in a certain limited number of actions it is designed to perform.

Take from the cell excavated by a digger wasp, the grasshopper she has placed there, and upon which sh has laid her egg, and the wasp, after entering and exploring the cell, will, instead of restocking it and laying another egg, calmly close it up, just as she would have done had it not been robbed.

Cut off the antennæ by which the wasp ( Sphex max illosus) drags a cricket to her burrow, and Sphex unable to get her accustomed grip, leaves her quarry, and goes off in search of crickets which have not lost their antennæ. It does not occur to her that the creature has legs as well as antennæ.

The sand wasp (Bembex) can unerringly return to the entrance to her cell from the distance of a mile or more, over a featureless sandbank, and although her burrow is covered over with sand, and to human eyes entirely indistinguishable from the parts surrounding it, the wasp can alight upon the exact spot scratch away the sand and enter the nest; but $r$ move the surface, exposing the cell and the larvi and Bembex is entirely at a loss, unable to recognize either her own nest or her own offspring. Nothing can more perfectly show how an interaction of forces, without a conscious, directing intelligence, can, in certain particular way, achieve a marvelous result

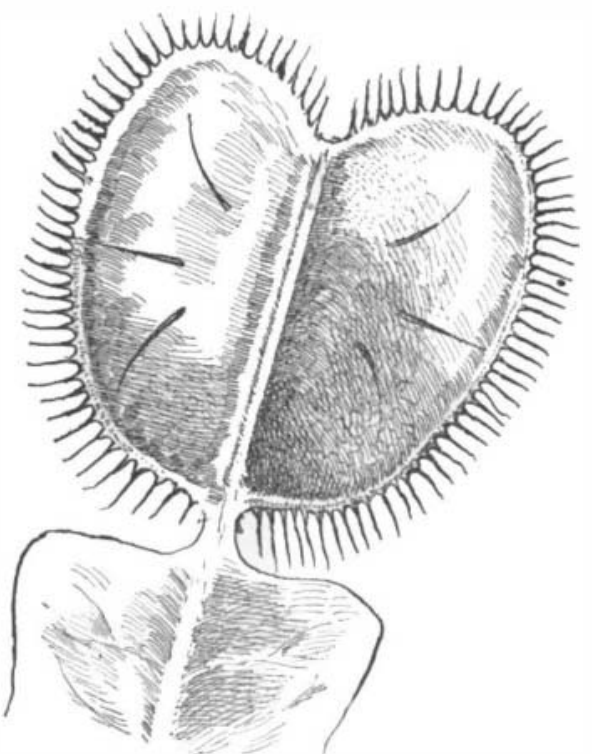

VENUS' FLYTRAP, OPEN.

while in every other, it results in confusion and failure. The unusual happens, and an organism constituted as is the Bembex, is thrown out of gear, much as would be a machine in which a cog-wheel has failed to engage the answering cogs of another wheel.

There are in plants fully as many ingenious devices to attain some desired end, and as many adaptations to special environments, perhaps, as among insects. Plants, however, rooted as they are to one spot and in general incapable of movement, exhibit contrivance in the only way left them to do so, in their habits of growth, and in the form and arrangement of their parts, as seen, for instance, in the manner in which many provide for the distribution of their seed, and the inventive faculty, so to speak, shown in the modifications of form in orchids to secure fertilization. I say in general incapable of movement, because the rule admits of very notable exceptions.

In the telegraph plant (Desniodium gyranus) of India, of the three leaflets of which each of its leaves are composed, the larger terminal one erects itself during the day, and turns sharply down at night, while the other two smaller leaflets move constantly day and night, describing complete circles with a peculiar jerking motion like the second hand of a watch. Occasionally they rest for a period and then go on again, thus bringing every part of every leaf to the full action of the sunlight.

Many plants shift the position of their leaves as the direction of the light changes. This power is possessed to a considerable degree by some of our common house plants. If an oxalis shrub, for instance, is exposed for a time to the light in a window, and then turned half way around, an observer can by watching, see the leaves readjust themselves to their new position in relation to the light. Certain movements of plants seem to testify to the possession by the plants of something answering to the tactile sense in animals. A number of plants besides the common sensitive plant, exhibit apparent sensibility to external impressions and manifest also the power of transmitting the perception of these impressions from one part of the plant to another. In addition to this power, there are plants which possess a power of disc r i m i n a tion that certainly seems to have as just a claim to being called intelligent as are the actions of some in sects.

If a drop of wat e $r$, or a grain of sand, falls upon the gland - studded leaves of the s u n d e w (D $r$ os er $a)$, nothing more happens than as if they had been dropped upon the leaf of any ordin a ry plant; but let an insect or a bit of meat tak

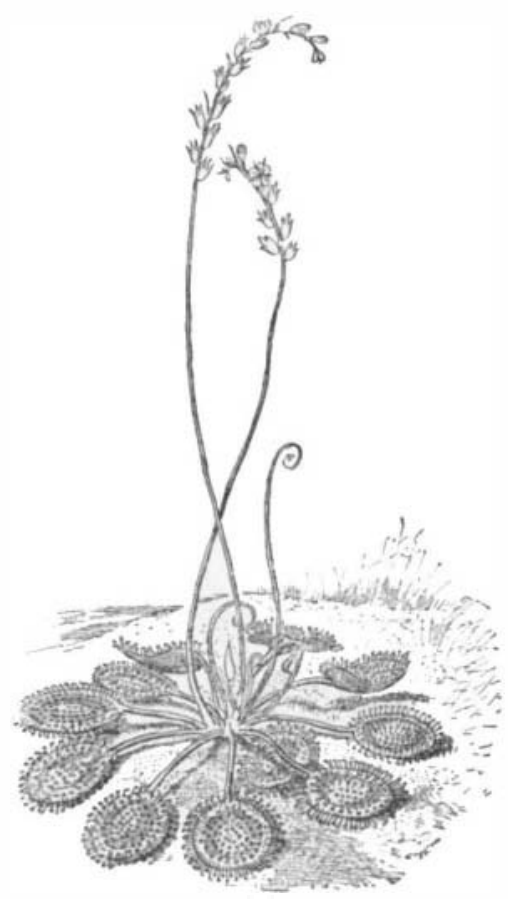

SUKDEW. 
the place of these in nutritious substances, and you shall see the tentacular glands gradually bend over, and assisted by the curling up of the leaf itself, enfold the esculent morsel, and cover it with a digestive fluid, which at once dissolves it and adapts it to be assimilated by the insect-eating plant. But it is worthy of note that the instinct of the plant, under certain exceptional circumstances, like the instincts of insects, sometimes goes wrong; for the sundew as eagerly accepts morsels of cheese as it (ioes of any other nitrogenous substance, and cheese is a poison to the Drosera plant. The sundew is not the only plant which exercises choice and discrimination in the selection of its food. In and about the swamps of North Carolina, and indeed in many other parts of the United States, is found the Dioncea, or Venus' fly-trap. It has, as has the Drosera, very small roots, which, like those belonging to the sundew, serve only to give it a foothold, and supply it with moisture the plant captures the food necessary to its subsistence. The leaf blade is constructed like a steel trap, the two halves snapping together, and the marginal teeth interlocking as do the teeth of a trap. Long sensitive bristles, generally three in number, arranged in a triangular order, erect themselves upon the upper surface of the trap. Touched ever so slightly by a hovering or flying insect, they transmit an impulse which in an animal would be called a mandate of its will, to the muscles or the machinery that moves the lobes of the trap, and so instantly is this obeyed, that these lobes close upon the insect and capture it. Inorganic bodies placed upon the lobes, unless they touch the sensitive filaments, do not cause them to close; organic bodies when moistened and placed upon the leaf, cause it, after absorption has begun to take piace, to close slowly. The lobes may be made to close over either organic or inorganic substances, but with a difference. When an inorganic substance is placed upon the leaf, and one of the sensitive bristles is touched, the leaf indeed shuts up, but in such a manner as to leave a hollow space between the lobes of the trap; it is as if the plant were tasting the substance to see if it were fit for food. When, on the other hand, an organic substance falls upon the leaf, both lobes press against it and against each othe with force enough to flatten out a portion of the white of a hard-boiled egg, that they have been made to close upon. Again, when any innutritious substance is caught, the glands are not excited to secrete the digestive fluid, and the lobes soon open, freeing the substance and showing it perfectly dry. If the object caught is too small to make it worth the attention of the plant, it is allowed to escape between the interlecking teeth; but if the quarry be large enough, and of a nutritious character, the lobes will remain flattened together over it for fifteen, twenty-four, or even thirty-five days.

Darwin, speaking of the sensitiveness of root tips, shows that they have developed diverse kinds of sensitiveness, so that "it is," he says, "hardly an exag. geration to say that the tips of the radicle thus endowed, and having the power of directing the movement of the adjoining parts, act like the brain of our lower animals, the brain being seated within the anterior end of the body, and directing the several movements."

The wonderful power of this substitute for a brain as shown in its leading the parts to which it is at tached over, under, or around every intervening obstacle through the dark earth to a more or less distant water supply, or a rich deposit of nitrogenous nutriment in the form of a buried carcass, is it not quite as wonderful as the faculty of the bee in flnding its way to its nest, or of a male moth discovering from a great distance the locality where a female of the same species is hidden?

Of course only the merest glimpse at the wonderfu reflex action of plants can be here given, but a more extensive investigation of the subject leaves the student impressed with the fact that both plants and insects develop along narrow lines a perfection of power in adapting means to an end that nothing in the plant or in the insect can at all account for, and that as students of Nature are beginning to believe, no serie of merely fortuitous, aggregated variations can explain.

As the construction of the Nile reservoir at Assouan involves the unavoidable submersion of a portion of the temple of Philæ, situated upon the island of Phile, the Egyptian government has decided to take all possible steps to preserve a record of these monuments a they existed prior to the rise in the water levels, and also to lessen any danger which might arise from the annual inundation. The record of these historic monuments has been completed, and now to insure the st bility of the structures the foundations of the temples are being underpinned. As the foundations of the temple of Isis were found to descend everywhere to the solid rock, it was decided to limit the operations to the consolidation of the other structures. It is exthe consolidation of the other structures. It is ex-
pected that the work will be entirely completed in the course of a few weeks.

\section{MIXING POMP.}

The blending of whisky and the rectification of spirits in general is based on the fact that cheaper qualities can be improved considerably by the addition of comparatively small quantities of higher grade goods, certain essential oils, and other ingredients. To effect such an amelioration, it is a matter of the utmost importance that all constituent parts are not only poured together, but that the mixture is thoroughly stirred and repeatedly agitated, that all particles may mingle freely and every ingredient become distributed most minutely. Only by infinite diffusion and energetic agitation can the different parts of the mixture act upon each other chemically, and effect

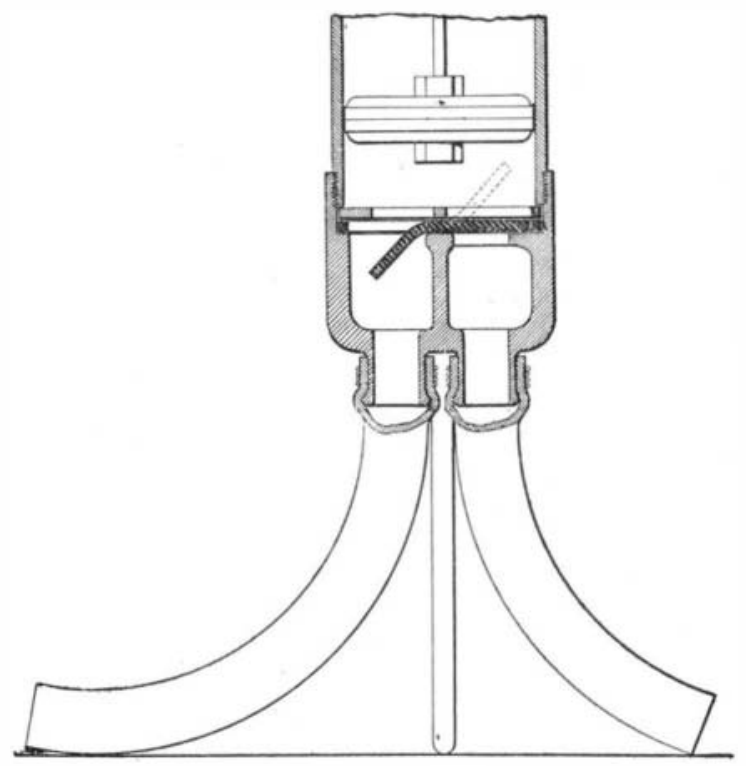

\section{DIAGRAM OF THE MIXING PUMP.}

a blend of uniform character that bears the savor of "age," otherwise obtained only as the result of years of careful storage and maturation. This vital poin of stirring up and agitating the mixture is too fre quently neglected, especially in smaller establishments with limited storage facilities, where ingredients are added to liquor already within the barrels. The shaking of the barrel or package is certainly insuf ficient to mix the heavy sirup and other sweetening matter with the light spirits, particularly in moderat temperatures. Nor can the oils be properly diffused by the mere rolling of the barrels or stirring with stick through the narrow bunghole. Stirring in open tanks has the great disadvantage of reducing the strength in alcohol and aroma, by continually exposing new parts of volatile matter to the air. Unde certain conditions this renders liquor cloudy through

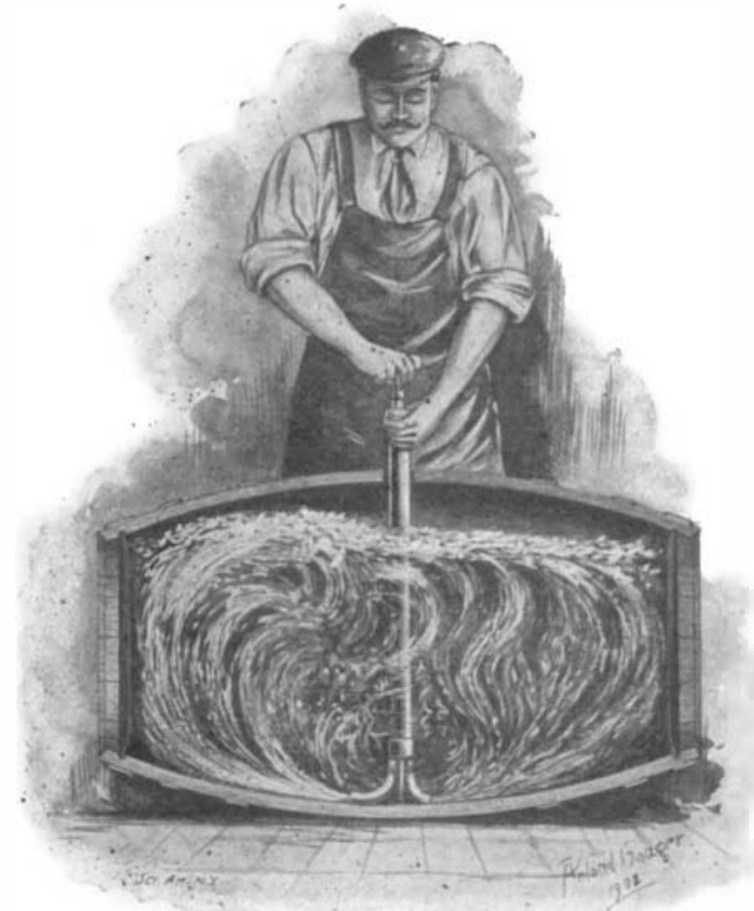

MIXING POMP IN OPERATION.

the oxidation of essential oils exposed in this manner. To achieve the best possible results it is necessary that the stirring be done most energetically near the bottom of the vessel, where sirup and cther heavy matter will settle; that part of the mixture be orced into the rest with a certain pressure, thus creating a strong current and numerous whirls throughout the tank or barrel; and that the air. be excluded as much as possible.

A simple and effective tool, that complies with al these requirements, is a mixing pump just patented by $\mathrm{Mr}$. Herman Soellner, of 842 Bushwick Avenue Brooklyn, N. Y. One of our views shows th Brooklyn, N. Y. One of our views shows the
pump in operation, while the construction is clearly pump in operation, while the construction is clearly
indicated in the diagram. The plunger fits snugly in a eylinder, at the bottom of which is a double nozz controlled by a double valve. Connected to the nozzles are two sections of rubber hose, while a metal spu in the center serves to hold the pump in proper operative position. Now, when the plunger is drawn up ward the rubber valve-disk is sucked up, closing the left-hand nozzle, but opening the nozzle at the right, as indicated by dotte lines. The cylinder will thus be filled with the liquid, which on the downward stroke is discharged through the left-hand nozzle. Repetition of this process results in establishing current through the liquor, which thoroughly mixe all the elements. The discharge pipe, it will be noticed, is longer than the receiver. The purpose of the former is to direct the current in a whirl that embraces the entire contents of the barrel, while the latter pipe receives its supply from the bottom, where the heavier matter is most apt to settle. From a practical point of view this tool fills every want. It can be used in a tank as well as in a barrel of any size. Its simplicity, lightness and easy manipulation appeal to the workman, who can assume a comfortable position, slip the mixer through the narrow bunghole and achieve all that is required within a few seconds. All parts of the mixer are interchangeable, indifferent to alcoholic solutions of any strength and need no cleaning other than rinsing to remove the characteristic flavor of the respective liquors. The utility of this mixing pump is not limited to the rectification business only, as it will mix fluids of the most different chemical nature and speciflc gravity. It causes a perfect solution and disintegration of salts, oils, chemicals, paints, etc., and also distributes insoluble matter, such as charcoal, boneblack, and other materials.

\section{French Competition for Belt Mounters.}

The numerous accidents to workmen in establishments where belts are used has recently brought about the stringent application of a French law, forbidding the removing or replacing of a strap by hand while the machinery is in motion.

In order to obviate the waste of time consequent upon the stopping of the machinery, an association of French manufacturers has announced an open international competition for the best fixed belt mounter.

The invention should be designed for simple and not for conical pulleys, and must comply with the following conditions:

(1) It must be simple, strong, and occupy little space; easy to fix and use.

(2) Not dangerous in workin belt.

(4) Able to throw the belt off or on

(5) Sufficiently low in price to allow of its wide use. Competitors are invited to send a full description of their invention, accompanied, if possible, by a model or at least by satisfactory illustrations, to the president de l'Association des Industries de France contre les Accidents du Travail, No. 3 rue Lutèce, Paris, prior tc October 1, 1902

This notice may be of interest to American inventors or to firms dealing in machinery of this character.

\section{The Current supplement.}

The first article in the current Supplement, No. 1381 , is a well-illustrated account of rice culture in the United States, by Dr. 'S. A. Knapp. Of technological interest is an illustrated description of the mechanical manufacture of bottles. A new army pistol used in Switzerland, and called the "Parabellum," is made the subject of an article, accompanied by several engravings. An entertaining essay by Frank $\mathrm{Hix}$ Fayant tells how electrical engineers are trained. William A. Del Mar, who has contributed to the SupPLEMENT many articles of practical interest, describes graphically how a modern coherer is made, and tells something of its history as well. The use of oxygen in cases of carbon monoxide poisoning may be of value to physicians. H. M. Miller pictures the manners and customs of the people of Southern Borneo. A very ful treatise on carbureters will interest some of our automobile readers. The Consular Notes and Selected Formulæ will be found in their usual places.

\section{International Navigation Congress.}

From June 29 to July 5, 1902, the Ninth International Navigation Congress will be held at Diisseldorf. The aim of the Congress is the encouragement, promotion and improvement of navigation, as well as the exchange of experiences gained. Technical and economical questions relating to inland and ocean navigation will be discussed.

Oscar McClellan, a printer, inventor and bosom friend of Edgar Allan Poe, died at his home in Philadelphia recently at the aga of 82 years. He was an inventor of some noto, and three times had placed himself in an independent position through his inventive genius. His last achievement in this line was an improvement on a machine for performing some of the operations of shoe-making, for which improvement he received $\$ 80.000$ in royalties. 